\title{
Surgical management of a case of recurrent carcinoma cervix: a case report
}

\author{
B. Kalpana ${ }^{1}$, S. G. Balamurugan ${ }^{2} *$ Soumya Ranjan Panda ${ }^{3}$
}

\author{
${ }^{1}$ Department of Reproductive Medicine, Guru Hospital, Madurai, Tamil Nadu, India \\ ${ }^{2}$ Department of Surgical Oncology, Guru Hospital, Madurai, Tamil Nadu, India \\ ${ }^{3}$ Department of Obstetrics and Gynecology, AIIMS, Mangalagiri, Andhra Pradesh, India
}

Received: 05 February 2020

Accepted: 29 February 2020

\section{*Correspondence:}

Dr. S. G. Balamurugan,

E-mail: balamurugan_kalpana@rediffmail.com

Copyright: (C) the author(s), publisher and licensee Medip Academy. This is an open-access article distributed under the terms of the Creative Commons Attribution Non-Commercial License, which permits unrestricted non-commercial use, distribution, and reproduction in any medium, provided the original work is properly cited.

\begin{abstract}
Worldwide cervical cancer is the fourth most common cancers among females. Pelvic recurrence, distant metastases, or a combination of both can occur in patients of carcinoma cervix. A 42-year-old P2L2 with a history of carcinoma cervix stage 3-b came to our OPD for routine follow up. Two year back she was managed with chemoradiation for her primary carcinoma which had parametrium extension. There was a $1 \times 1 \mathrm{~cm}$ lesion on the anterior vaginal wall which was diagnosed to be cervical recurrence. Patient underwent total abdominal hysterectomy with bilateral salpingooophorectomy with pelvic lymphadenectomy. Patient is disease free till now. Treatment decisions should be individualised based on the performance status of the patient, the site of recurrence and/or metastases, the extent of metastatic disease, and prior treatment.
\end{abstract}

Keywords: Carcinoma cervix, Pelvic recurrence

\section{INTRODUCTION}

Worldwide cervical cancer is the fourth most common cancers among females. Pelvic recurrence, distant metastases, or a combination of both can occur in patients of carcinoma cervix. Following primary surgery or radiotherapy in women with stage IB-IIA cervical tumors with no evidence of lymph node involvement, the recurrence rate has been reported to be around $10 \%$ $20 \%$. While the relapse rate of those with nodal metastases and/or more locally advanced tumors is up to $70 \%{ }^{1-4}$ The majority of recurrences occur within 2 years of diagnosis, and the prognosis is poor, with most patients dying as a result of uncontrolled disease. Treatment decisions should be individualised based on the performance status of the patient, the site of recurrence and/or metastases, the extent of metastatic disease, and prior treatment. ${ }^{5}$ Performing radical hysterectomy for patients with recurrent carcinoma cervix is rarely done. Here the case is describing recurrent carcinoma cervix for which this case performed surgical management.

\section{CASE REPORT}

A 42-year P2L2, with a history of carcinoma cervix stage $-3 \mathrm{~B}$, came to study OPD for routine follow up. Two-year back she was managed with chemoradiation for her primary carcinoma which had parametrium extension. She was a known case of diabetes mellitus on medication. On examination there was mild pallor and rest of her general and abdominal examination findings were within normal limit. On per speculum examination there was a lesion of size $1 \times 1 \mathrm{~cm}$ in anterior vaginal wall extending from cervix. CT scan was reported as bulky vaginal wall. Biopsy of the lesion revealed it to be mucin secreting adenocarcinoma. So, a provisional diagnosis of recurrent carcinoma cervix was made. Patient underwent radical 
hysterectomy with bilateral salpingooophorectomy with pelvic lymphadenectomy (Figure 1 and 2). The intraoperative and postoperative course was uneventful and she was discharged on $7^{\text {th }}$ post-operative day. Patient is disease free till now.

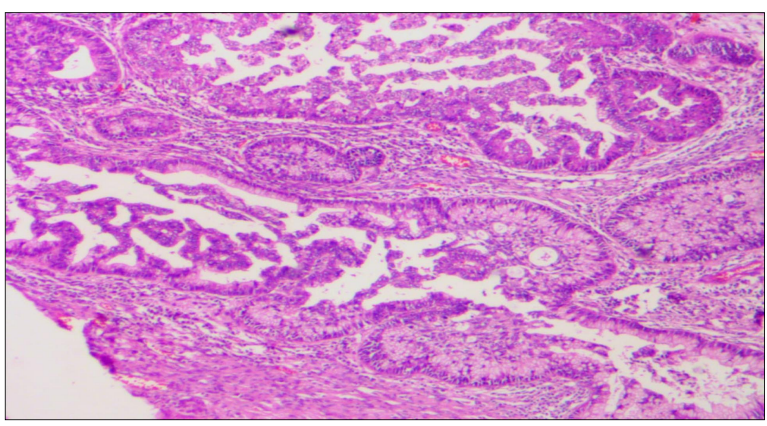

Figure 1: Histopathology picture showing moderately differentiated adeno carcinoma of cervix.

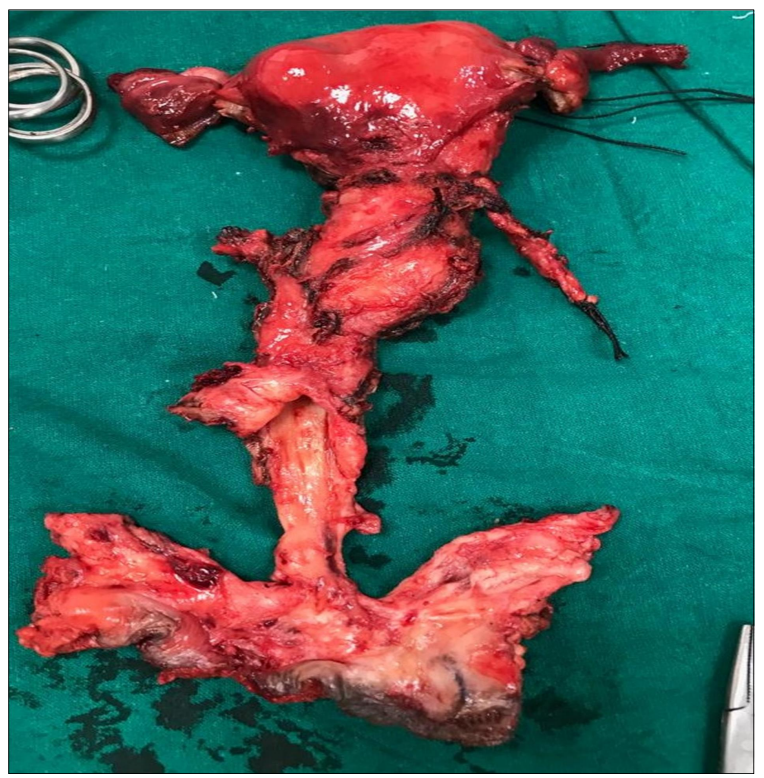

Figure 2: Surgical specimen.

\section{DISCUSSION}

Recurrence rates of carcinoma cervix have been described from 30 to $60 \%$. Previous laparotomy, previous radiation, radiation $>6,000 \mathrm{cGy}$ to the pelvis, radiation within 1 year of exenterative surgery, weight $>200 \mathrm{lb}$, age $>60$ years, margin status, node status, and triad of trouble-hydronephrosis, leg edema, and leg pain are some of the factors that are associated with an increased risk of recurrence. $^{6-9}$

A thorough clinical examination should be performed to define the type of recurrence, central recurrence versus a lateral or diffuse recurrence. Central disease is a relatively homogeneous tumor usually derived from the retained cervix and vagina in case of primary radiation or from the vaginal cuff and central scar where surgery was opted as primary therapy. Central disease may extend to the pelvic side wall. ${ }^{10}$ In contrast, side wall disease is heterogeneous. Most pelvic recurrences have a diffuse growth pattern fixed to one or both pelvic side walls. These fixed recurrences are felt at physical examination as "pelvic fibrosis" with or without a dominant mass. Thus, pelvic fibrosis is an ominous finding significantly related to nodal disease and fixation to pelvic side wall. Such recurrences are common after surgery followed by radiotherapy. Most patients who relapse locally after primary radiotherapy are not candidates for further radiotherapy, and pelvic exenterative surgery is the only potentially curative approach for these patients. The 5year survival rate for patients who undergo total pelvic exenteration ranges from 30\%-60\%. ${ }^{11-16}$ Identification of the clinical and histopathological factors that predict recurrence and survival after pelvic exenteration may improve the ability to better select patients who are potentially curable with radical surgery. The prognostic factors that have been identified include disease-free interval, size of recurrence, and preoperative lateral side wall fixation. ${ }^{8-12}$ The prognosis is better for patients with a disease-free interval greater than 6 months.

Several authors have reposted the use of radical hysterectomy to treat patients with recurrent or persistent uterine cancer following definitive radiotherapy/ chemoradiation. ${ }^{17-19}$ With the current advances in radiotherapy delivery techniques, the recurrences rates have reduced and such procedures have become a rarity. Patients up to $2 \mathrm{~cm}$ lesion, confined to the cervix with no evidence of hydroureteronephrosis, are candidates for the procedure. As for any surgery performed after radiotherapy, there is a higher incidence of complications after this procedure. The complications include urinary tract infections, wound-related complications, thromboembolic complications, bowel obstruction, bladder dysfunctions and voiding problems, ureteral injury, and vesicovaginal and rectovaginal fistulae. ${ }^{20}$

\section{CONCLUSION}

Recurrence rates of carcinoma cervix have been described from 30 to $60 \%$. A thorough clinical examination should be performed to define the type of recurrence, central recurrence versus a lateral or diffuse recurrence. Identification of the clinical and histopathological factors that predict recurrence and survival after pelvic exenteration may improve the ability to better select patients who are potentially curable with radical surgery. Treatment decisions should be individualised based on the performance status of the patient, the site of recurrence and/or metastases, the extent of metastatic disease, and prior treatment.

\section{Funding: No funding sources Conflict of interest: None declared \\ Ethical approval: Not required}




\section{REFERENCES}

1. Delgado G, Bundy B, Zaino R, Sevin BU, Creasman WT, Major F. Prospective surgical-pathological study of disease-free interval in patients with stage IB squamous cell carcinoma of the cervix: a gynecologic oncology group study. Gynecol Oncol. 1990;38:352-7.

2. Zaino RJ, Ward S, Delgado E, Bundy B, Gore H, Fetter $\mathrm{G}$, et al. Histopathologic predictors of the behavior of surgically treated stage IB squamous cell carcinoma of the cervix. A Gynecologic Oncology Group study. Cancer. 1992;69:1750-8.

3. Burghardt E, Baltzer J, Tulusan AH, Haas J. Results of surgical treatment of 1028 cervical cancers studied with volumetry. Cancer. 1992;70:648-55.

4. Stehman FB, Bundy BN, DiSaia PJ, Keys HM, Larson JE, Fowler WC. Carcinoma of the cervix treated with radiation therapy. I. A multi-variate analysis of prognostic variables in the Gynecologic Oncology Group. Cancer. 1991;67:2776-85.

5. Friedlander M, Grogan $M$. Guidelines for the treatment of recurrent and metastatic cervical cancer. Oncol. 2002;7:342-7.

6. Karlan JR, Piver MS. Reduction of mortality and morbidity associated with pelvic exenteration. Gynecol Oncol. 1975;3:154-67.

7. Rutledge FN, Smith JP, Wharton JT. Pelvic exenteration: analysis of 296 patients. Am J Obstet Gynecol. 1977;129:881-92.

8. Symmonds RE, Pratt JH, Webb MJ. Exenterative operations: experience with 198 patients. Am J Obstet Gynecol. 1975;121:907-18.

9. Stanhope CR, Symmonds RE. Palliative exenteration- what, when and why? Am J Obstet Gynecol. 1985;152:12-6.

10. Ho“ckel M, Baussmann E, Mitze M, Knapstein PG. Are pelvic side-wall recurrences of cervical cancer biologically different from central relapses? Cancer 1994;74(2):648-55.
11. Shingleton HM, Soong SJ, Gelder M, Hatch KD, Baker VV, Austin JJ. Clinical and histopathologic factors predicting recurrence and survival after pelvic exenteration for cancer of the cervix. Obstet Gynecol. 1989;73:1027-34.

12. Rutledge FN, Smith JP, Wharton JT, O'Quinn AG. Pelvic exenteration: analysis of 296 patients. Am J Obstet Gynecol. 1977;129:881-92.

13. Symmonds RE, Pratt JH, Webb MJ. Exenterative operations: experience with 198 patients. Am J Obstet Gynecol. 1975;121:907-18.

14. Stanhope CR, Symmonds RE. Palliative exenteration-what, when and why? Am J Obstet Gynecol. 1985;152:12-6.

15. Matthews CM, Morris M, Burke TW. Pelvic exenteration in the elderly patient. Obstet Gynecol. 1992;79:773-7.

16. Estape R, Angioli R. Surgical management of advanced and recurrent cervical cancer. Semin Surg Oncol. 1999;16:236-41.

17. Adcock LL. Radical hysterectomy preceded by pelvic irradiation. Gynecol Oncol. 1979;8:152-63.

18. Friedell GH, Cesare F, Parsons L. Surgical treatment of cancer of the cervix recurring after primary irradiation therapy. N Engl J Med. 1961;264:781-4.

19. Rubin SC, Hoskins WJ, Lewis JL. Radical hysterectomy for recurrent cervical cancer following radiation therapy. Gynecol Oncol. 1987;27:316-24.

20. Coleman R, Keeney E, Freedman R, Burke T, Eifel $\mathrm{P}$, Rutledge F. Radical hysterectomy for recurrent carcinoma of the uterine cervix after radiotherapy. Gynecol Oncol. 1994;55:29-35.

Cite this article as: Kalpana $\mathrm{B}$, Balamurugan $\mathrm{SG}$, Panda SR. Surgical management of a case of recurrent carcinoma cervix: a case report. Int J Reprod Contracept Obstet Gynecol 2020;9:1721-3. 